\title{
Affordability of essential medicine prices in Malaysia's private health sector
}

This article was published in the following Dove Press journal:

Patient Preference and Adherence

\section{Nur Sufiza Ahmad' \\ Farida Islahudin ${ }^{2}$}

'Pharmaceutical Services Division, Ministry of Health Malaysia, Petaling Jaya, Malaysia; ${ }^{2}$ Faculty of Pharmacy, Universiti Kebangsaan Malaysia, Kuala Lumpur, Malaysia
Correspondence: Farida Islahudin Faculty of Pharmacy, Universiti Kebangsaan Malaysia, Jalan Raja Muda Abdul Aziz, 50300 Kuala Lumpur, Malaysia

Tel +60 392897689

Email faridaislahudin@yahoo.com
Background: The lack of price control in Malaysia has led to increased market competition, resulting in high medicine prices, notably in the private sector. This largely affects patients' out-of-pocket expenses in the private sector. Although generic medicines are preferred due to affordability, the prices are still notably high.

Methods: This study compares innovator and generic medicine prices to estimate treatment affordability in the private sector. Private hospitals and community retail pharmacies were examined from 2011 to 2015. Data were collected on the basis of recommendations by the World Health Organization's Health Action International.

Results: The markup of generic medicines was significantly higher than that of innovator medicines during the study period $(p<0.001)$. While the markup of generic medicine was $31 \%-402 \%$ (36\%-171\% and 31\%-402\% for core and supplementary list items), that of innovator medicine was $24 \%-86 \%(28 \%-86 \%$ and $24 \%-80 \%$ for core and supplementary list items). There was no significant increase in the median price ratio for 11 selected generic medicines (from $1.8 \pm 3.9$ to $2.9 \pm 8.2)(p>0.05)$. However, the median price ratio of the 11 innovator medicines significantly increased (from $4.9 \pm 6.1$ to $11.2 \pm 20.3$ ) ( $p=0.045$ ). Affordability of all generic medicines was below the 2-day wage for treatment, with captopril (25 mg tablet) reporting the highest cost (1.1-1.7-day wages). Among innovator medicines, omeprazole (20 mg capsule; 6.2-7.0 days' wages) reported the highest median treatment cost.

Conclusion: There is a need for policies to control national drug prices, to ensure medicine prices are monitored. This can help keep out-of-pocket expenses, especially in middle-income countries such as Malaysia, at a minimal in the private sector.

Keywords: community medicine, patient education, pharmacy, hospital

\section{Introduction}

High medicine prices and low affordability are key factors impeding accessibility to treatment in developing countries. ${ }^{1}$ In Malaysia, the healthcare system provides medicines to the public through 2 main systems: the government-funded public sector and self-sustaining private sector. ${ }^{2}$ Although medicines can be accessed free-of-charge through public hospitals and clinics, a large number of patients prefer to acquire their medication from private hospitals and community pharmacies. A survey performed in Malaysia revealed that only $13 \%$ of the population received free-of-charge medication under the public healthcare system, whereas the remaining $87 \%$ incurred payment schemes and out-of-pocket expenses from the private sector. ${ }^{3}$ This could lead to significantly high medication expenditure, thus emphasizing the need to ensure medication affordability in local setting.

Medicine affordability can be controlled through medication price policies. ${ }^{1}$ Globally, various price regulation schemes have been put into effect, such as the National 
Pharmaceutical Pricing Authority in Britain and social insurance schemes in Germany and Japan. ${ }^{4}$ Price regulation policies typically cap prices that dominant companies charge for medication, making medication far more affordable for the less fortunate. ${ }^{5}$ Unfortunately, no price control policies have been implemented in Malaysia and, as such, pharmaceutical industries may have greater control over the market prices of medicines. The lack of price control leads to the markup of medicines in the pharmaceutical supply chain, which in turn contributes to the overall hike in drug prices.

Steadily increasing health expenditures have become a global concern. ${ }^{1}$ In Malaysia, health expenditure increased from RM 38.63 billion in 2011 to RM 44.78 billion in $2013,{ }^{6}$ which translates into RM 18.195 billion and RM 21.495 billion in the private sector. ${ }^{6}$ Medicine prices in Malaysia have also been shown to escalate at a much higher rate than other countries. ${ }^{4}$ Thus, medication affordability is particularly a problem in countries where chronic disease, such as diabetes and hypertension, are major problems given the lifelong nature of treatment required. ${ }^{2}$

Ensuring equitable access to pharmaceuticals is, therefore, an essential component in healthcare systems. A recent work addressing the issue of medicine pricing in local settings suggests the need to closely monitor medicine prices and affordability. ${ }^{7}$ Patients' preference toward private healthcare facilities in the local setting ${ }^{3}$ also suggests the need to ensure prices are monitored. Subsequently, the Malaysian National Medicines Policy was set up to provide strategic guidance on the overall development of a pricing policy to ensure access to affordable medicines for all citizens. ${ }^{8}$

This study is performed as part of the Malaysian National Medicines Policy and compares medication prices between private hospitals and community pharmacy in the private sector. In view of the high number of population receiving health care from private facilities through payment schemes and out-of-pocket expenses, prices of medicines could vary largely between private healthcare settings. ${ }^{1,2,6}$ In general, private hospitals are paid through payment schemes, while community pharmacies are borne through out-of-pocket expenses. ${ }^{6}$ Therefore, due to the steady rise of medication prices, ${ }^{4}$ ensuring essential medicines remain affordable in the future requires further understanding of the possible price differences between private health care facilities. ${ }^{1,2,6}$ Furthermore, it is vital that consumers are not being inappropriately charged for generic medicines in the local setting. Thus, this study aims to compare the prices of innovator and generic medicines and estimate affordability of essential medicines in the private sector in Malaysia.

\section{Methods \\ Study design}

This cross-sectional study was conducted annually for a duration of 2 weeks every July. The study period was 2011-2015. Healthcare facilities were selected from the private sector in the Peninsular and East Malaysia. Sampling areas were divided into 13 states and 3 federal territories. Hospitals and pharmacies were selected within a $5 \mathrm{~km}$ radius of each state public hospital with written informed consent given by all participants from each facility. All the information gathered was treated confidentially. This study was reviewed and approved by the Medical Research and Ethics Committee of the Ministry of Health Malaysia (ID No: NMRR-12-1415-12698).

\section{Selection of medicine}

The prices of 25 World Health Organization (WHO) core list medicines and 32 supplementary medicines were collected. ${ }^{9}$ The list of medicines was selected on the basis of the core list by WHO's Health Action International's and the most frequently used medicines in Malaysia..$^{9-11}$ Core medicines are used for a range of common acute and chronic conditions and recommended as first-line treatments in international, regional, and national guidelines. We also included supplementary medicines of local importance on the basis of the National Medicine Utilization Survey and Western Pacific Regional Core List recommended by Health Action International in 2012. ${ }^{10}$ Furthermore, 11 essential medicines included in the WHO Model List of Essential Medicines, ${ }^{10,11}$ were identified. Essential medicines are medicines that should be prioritized as healthcare needs of the population, ${ }^{10,11}$ and are also available in the core or supplementary lists. These are medicines that people should have access to at all times in sufficient amounts and at an affordable price. ${ }^{10,11}$ In each area, data collection was performed by an area supervisor. Data collectors received standardized training to ensure an accurate representation of medicine prices. The forms were then checked and any incomplete, erroneous, or illegible data were followed up by contacting relevant facilities to verify the data. A number of medicines were then randomly selected to verify prices, pack size, and availability.

\section{Medicine price}

Wholesale and retail prices of medicines were collected throughout the study period. Wholesale price is the procurement price of medicines available at the facilities during data collection. ${ }^{10}$ Procurement price data were collected if the facilities could produce invoices as evidence at the time. Retail price is the selling price set by the community 
pharmacy or private hospital for the patient or the customer. ${ }^{10}$ To gather relevant data, we collected displayed price labels or selling price lists available for the recommended pack size.

\section{Data analyses}

Data were analyzed using SPSS (version 21, IBM Corporation, Armonk, NY, USA) and reported as median, average, minimum, and maximum prices per standard unit. The exchange rate used was obtained from Bank Negara Malaysia. The rate per USD was an average of RM 3.00 (2011), RM 3.17 (2012), RM 3.19 (2012), RM 3.18 (2014), and RM 3.96 (2015). The price markup was calculated by subtracting the retail and wholesale prices. Median price ratio (MPR) was calculated for 11 essential medicines as determined by WHO. ${ }^{10,12}$ The MPR was calculated as the ratio of the median unit price to median international reference price in the same year, which was made available by the Management Sciences for Health. ${ }^{10,12}$ WHO recommends an MPR value of $\leq 2$. Affordability was calculated using the daily wage of the lowest-paid unskilled government worker by determining the number of days' wages required to purchase selected courses of treatment for common acute and chronic conditions. ${ }^{10,12}$

\section{Results}

A total of 46 (2011), 51 (2012), 57 (2013), 51 (2014), and 51 (2015) healthcare facilities in the private sector were recruited. The difference in the numbers of healthcare facilities in the private sector was due to the dropout of certain facilities and recruitment of others. However, a majority of the healthcare facilities were recruited over the period of 5 years.

\section{Generic medicine price}

The overall price increase for generic medicines was not significant from 2011 to 2015 for both core and supplementary medicines. Overall price is estimated as the average of both private hospitals and community pharmacy. The range of price increases for generic medicine was between 1.1- and 15.3-fold. The core list medicines with the highest increase in wholesale price were cotrimoxazole suspensions (15.3-fold) and fluconazole $200 \mathrm{mg}$ capsules (15-fold). This resulted in a retail price increase of 13.6-fold for cotrimoxazole suspension and 8 -fold increase for fluconazole $200 \mathrm{mg}$ capsules. Fluconazole $200 \mathrm{mg}$ capsule is also an essential list medicine. The supplementary list medicine with the highest wholesale price increase was chlorpheniramine $4 \mathrm{mg}$ tablet (1.3-fold), resulting in a 1.2-fold increase in the retail price of chlorpheniramine $4 \mathrm{mg}$ tablet.
A subanalysis of private hospitals and community pharmacy prices for generic medicines was performed. We found that during the study period, the core list medicine in the private hospital with the highest price increase was cotrimoxazole suspension (24.5-fold for wholesale price and 19.8-fold for retail price). In the community pharmacy, the highest price increase was for fluconazole $200 \mathrm{mg}$ capsule (22.7-fold for wholesale price and 15.3-fold for retail price), which was also an essential list item. For supplementary list medicines, the highest price increases in the private hospital were for diclofenac $50 \mathrm{mg}$ tablet (2.1-fold for wholesale price and 2.9-fold for retail price), an essential list item, and chlorpheniramine $4 \mathrm{mg}$ tablet (1.6-fold for wholesale price and 1.2-fold for retail price).

\section{Innovator medicine price}

The overall price increase during the study period for both core and supplementary list innovator medicines was not significant. The range of price increase was between 1.1and 4.7 -fold. The core list medicine with the highest price increase was ceftriaxone $1 \mathrm{~g}$ injection (4-fold for wholesale price and 4.7-fold for retail price), which is also an essential list medicine. For supplementary list medicines, the highest price increase was reported for chlorpheniramine $4 \mathrm{mg}$ tablet (1.9-fold for wholesale price and 2.7-fold for retail price).

We then performed a subanalysis of innovator medicine prices in the private hospital and community pharmacy. The core items with the highest price increase during the study period were ceftriaxone $1 \mathrm{~g}$ injection in the private hospital (4-fold for wholesale price and 4.7-fold for retail price) and diclofenac $25 \mathrm{mg}$ tablet in the community pharmacy (1.5-fold for wholesale price and 2.2-fold for retail price), both of which were also essential list items. Among the supplementary list medicines, chlorpheniramine $4 \mathrm{mg}$ tablet has the highest price increase in both the private hospital (2.1-fold for wholesale price and 1.3-fold for retail price) and the community pharmacy (3-fold for wholesale price and 3.2-fold for retail price).

\section{Price markup of medicines}

Next, we analyzed the mark-up of both generic and innovator medicines and found that the former was significantly higher than the latter during all 5 studied years $(p<0.001)$ (Figure 1).

The markup of generic medicine was $31 \%-402 \%$ (median 96\%) (36\%-171\% for core, $31 \%-402 \%$ for supplementary, and $49 \%-171 \%$ for essential list medicines). The generic core list item with the highest markup was glibenclamide $5 \mathrm{mg}$ 


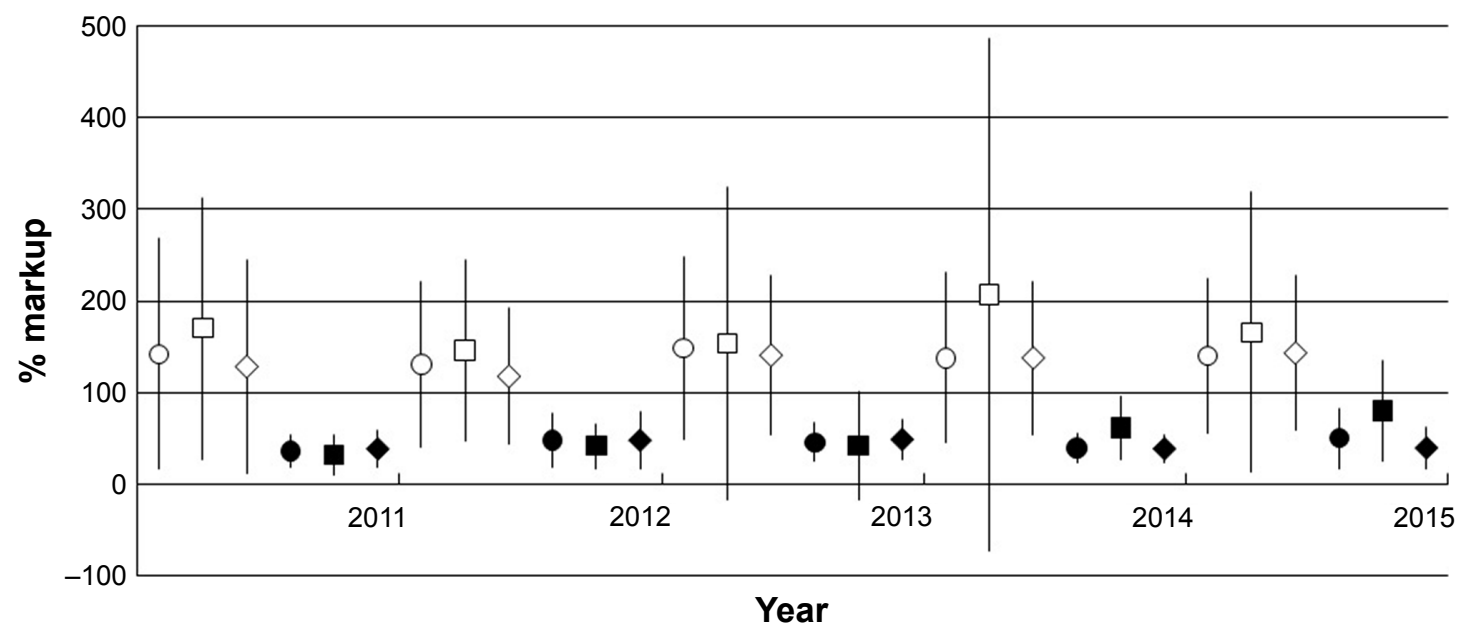

Figure I The average markup (\%) of generic and innovator medicine price (RM) (per unit), 20II-20I5.

Note: Symbols: $\bigcirc$ - overall generic price, $\square$ - private hospital generic price, $\diamond$ - community pharmacy generic price, $\bullet$ - overall innovator price, $\mathbf{\square}$ - private hospital innovator price, $\downarrow$ - community pharmacy innovator price.

tablet (171\% $\pm 16.9 \%)$, and for the supplementary list, it was chlorpheniramine $4 \mathrm{mg}$ tablet $(401.5 \% \pm 77.2 \%)$. Glibenclamide $5 \mathrm{mg}$ tablet is also an essential list medicine.

The markup of innovator medicines was $24 \%-86 \%$ (median 39\%) (28\%-86\% for core, 24\%-80\% for supplementary, and 31\%-86\% for essential list medicines). The highest average markup was found for ceftriaxone $1 \mathrm{~g}$ injection $(86.2 \% \pm 103.1 \%)$ in the innovator core list and salbutamol $2 \mathrm{mg}$ tablet $(79.8 \% \pm 7.2 \%)$ from the supplementary list. Both ceftriaxone $1 \mathrm{~g}$ injection and salbutamol $2 \mathrm{mg}$ tablets are also essential list medicines.

Other generic core list medicines that were marked up by $>100 \%$ were amitriptyline $25 \mathrm{mg}$ tablet, diclofenac
$25 \mathrm{mg}$ tablet, hydrochlorothiazide $25 \mathrm{mg}$ tablet, lovastatin $20 \mathrm{mg}$ tablet, and metformin $500 \mathrm{mg}$ tablet. Other generic supplementary list items with markup prices of more than $200 \%$ were diclofenac $50 \mathrm{mg}$ tablet, frusemide $40 \mathrm{mg}$ tablet, mefenamic acid $500 \mathrm{mg}$ tablet, salbutamol $2 \mathrm{mg}$ tablet, and simvastatin $10 \mathrm{mg}$ tablet.

\section{MPR and affordability}

MPR was calculated for 11 essential medicines as recommended by the WHO (Figure 2). We found a significant increase in the MPR of 11 innovator medicines from $4.9 \pm 6.1$ to $11.2 \pm 20.3$ ( $p=0.045)$ during the 5-year period. However, no significant increase was observed for generic medicines

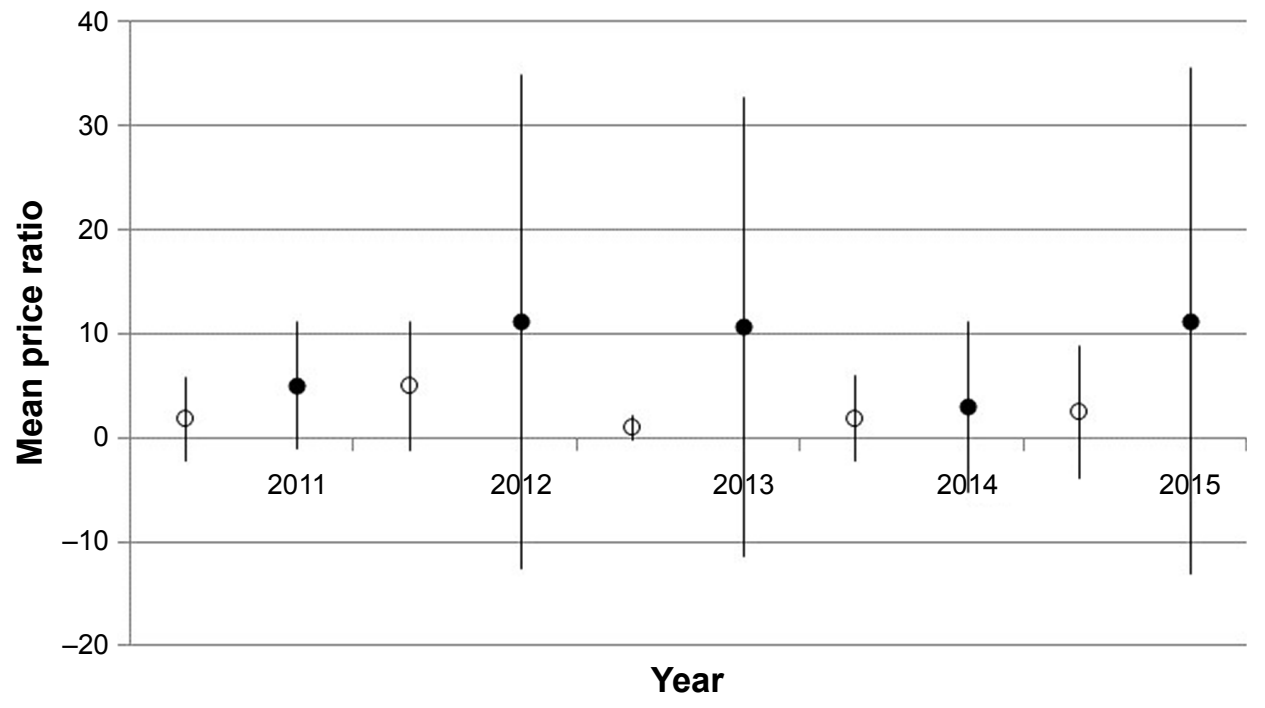

Figure 2 The average and SD of mean price ratios for both II essential generic and innovator medicines, 20II-20I5. Note: Symbols: $\bigcirc$ - generic medicine, $\bullet$ - innovator medicine. 
Table I Range of mean price ratio and median treatment cost (days) of II essential innovator and generic medicines, 20I I-20 I5

\begin{tabular}{|c|c|c|c|c|}
\hline \multirow[t]{2}{*}{ Generic name } & \multicolumn{2}{|l|}{ Innovator } & \multicolumn{2}{|l|}{ Generic } \\
\hline & $\begin{array}{l}\text { Median } \\
\text { price ratio }\end{array}$ & $\begin{array}{l}\text { Median treatment } \\
\text { cost (days) }\end{array}$ & $\begin{array}{l}\text { Median price } \\
\text { ratio }\end{array}$ & $\begin{array}{l}\text { Median treatment } \\
\text { cost (days) }\end{array}$ \\
\hline Amitriptyline 25 mg tablet & $0.3-0.4$ & $0.6-0.8$ & $0.3-0.32$ & $0.6-0.7$ \\
\hline Amoxicillin $250 \mathrm{mg}$ capsule & $0.3-0.5$ & $0.3-0.4$ & $0.4-0.7$ & $0.4-0.6$ \\
\hline Atenolol $50 \mathrm{mg}$ tablet & $1.4-1.6$ & $1.0-1.2$ & $0.3-0.4$ & $0.3-0.4$ \\
\hline Captopril 25 mg tablet & $1.3-1.4$ & 1.9 & $0.7-0.9$ & I.I-I.7 \\
\hline Ceftriaxone I g injection & $17.4-82.5$ & $0.4-1.9$ & $4.5-31.1$ & $0.1-1.0$ \\
\hline Ciprofloxacin $500 \mathrm{mg}$ tablet & $12.6-13.8$ & $4.1-4.8$ & $1.2-1.5$ & $0.4-0.7$ \\
\hline Diclofenac $50 \mathrm{mg}$ tablet & $1.4-1.8$ & $1.9-2.4$ & $0.3-0.4$ & $0.6-0.7$ \\
\hline Glibenclamide 5 mg tablet & $0.7-0.8$ & $0.9-1.0$ & $0.12-0.14$ & $0.2-0.3$ \\
\hline Omeprazole 20 mg capsule & $9.0-9.7$ & $6.2-7.0$ & $1.3-1.8$ & $0.9-1.3$ \\
\hline Salbutamol $100 \mu \mathrm{g} /$ dose inhaler & 0.1 & 0.6 & $0.06-0.2$ & $0.3-0.9$ \\
\hline Simvastatin $20 \mathrm{mg}$ tablet & $2.5-3.0$ & $1.7-2.2$ & $0.8-1.0$ & $0.7-1.0$ \\
\hline
\end{tabular}

Note: Median treatment costs (days) refer to number of days wages to complete treatment.

(from 1.8 \pm 3.9 to $2.9 \pm 8.2)(p>0.05)$. The range of the MPR for both innovator and generic medicines is shown in Table 1. An MPR of more than 2 was observed for essential innovator medicines, such as ceftriaxone $1 \mathrm{~g}$ injection (17.38-82.5), ciprofloxacin $500 \mathrm{mg}$ tablet (12.64-13.84), and simvastatin $20 \mathrm{mg}$ tablet (2.54-3.0). For essential generic medicines, ceftriaxone $1 \mathrm{~g}$ injection had an MPR of $>2$ (4.5-31.1).

Table 1 presents the affordability of medicines analyzed. The essential innovator medicines with the highest median treatment cost in days were omeprazole $20 \mathrm{mg}$ capsule (6.2-7.0 days' wages for treatment) and ciprofloxacin $500 \mathrm{mg}$ tablet (4.1-4.8 days' wages for treatment). However, the affordability of all essential generic medicines was below 2 days' wages for treatment, with the highest being for captopril $25 \mathrm{mg}$ tablet (1.1-1.7 days' wages for treatment).

\section{Discussion}

The impact of high medicine prices on the sustainability of health care is a growing issue, and the free market system in local settings has sparked further concerns over medication prices. ${ }^{1,7}$ As such, acrimonious debates over drug prices and drug control policies have been ongoing given the direct effect of medicine affordability. To this effect, a medicine price unit was set up to oversee and monitor medicine price markups throughout Malaysia. ${ }^{13}$ However, the most recent work on drug pricing and affordability in Malaysia showed that the free market was unable to control the markup of medicine prices and led to large variations in medication price increases, notably in the private sector. ${ }^{7}$ The current work, which focused on the private sector, obtained similar results.

Access to medication in the private sector is mainly provided by private hospitals and community pharmacies. ${ }^{7}$
However, it has been observed that the wholesale prices of medicine largely differ between the 2 institutions. During the 5-year study period, the increase in wholesale prices differed by drugs and type of private setting, which led to a parallel increase in retail prices. The large variation depicts the extent to which medicine prices not under price control are left to market forces, ${ }^{14}$ which is similar to previous observations. In addition, we noted that anti-infectives and antihistamines were largely affected by price increases in both generic and innovator medicines in the private sector. This suggests that the high use of both medicine classes ${ }^{14}$ in the private setting may have been triggered by a price increase.

The markup of both innovator and generic medicine was 3- to 4-fold higher than that previously reported in Malaysia. ${ }^{7}, 15$ Generic medicine was observed to have a significantly higher markup than innovator brands and has been a target of substantially high markup prices in most countries, ${ }^{16}$ which can be attributed to a low baseline cost. The low baseline cost of generic medicines allows the private sector to increase prices at a higher level while maintaining affordability when compared to innovator costs. This gives the impression of a cheaper option when compared to innovator medicines while ignoring the lower-income population that can ill-afford the markedup generic prices. The median markup of medicines in Thailand's private sector was $22 \%$ for innovator medicines ${ }^{17}$ which is much lower than the $39 \%$ presented in this study. However, the median markup price of generic medicine in Thailand was $96 \%,{ }^{17}$ which is similar to the present findings.

In addition, we found that the markup of medicine prices was generally higher in private hospitals than community pharmacies. In Malaysia, payment of treatment in private hospitals are usually through payment schemes, and hence 
prices of medicines in private hospitals are rarely disclosed in detail to the patient, but rather charged directly to the insurance companies. ${ }^{2-4}$ On the other hand, community pharmacies choose to reduce medicine prices to attract customers and remain competitive in the pharmaceutical market. This also holds true for community pharmacies in other countries such as China. ${ }^{18}$ However, despite remaining competitive, the prices of medicines have recently spiked owing to the increase in demand. This was clearly observed for antiinfectives and antihistamines in the present study. Unfortunately, both medicines remain key therapeutic tools. As such, the increase in prices largely affects the disadvantaged as associated price increases are borne through substantial out-of-pocket payments.

To further appreciate the affordability of medicines in Malaysia, 11 essential medicines from the core and supplementary list were then used for comparison. ${ }^{10,12}$ In Malaysia, despite a high MPR for certain medicines, affordability remains comparable to the recommendations of the WHO. ${ }^{10}$ Despite the slightly higher markup of essential generic medicines, MPR of essential innovator medicines were observed to be higher. This difference could be attributed to the generally low cost of generic medicines in Malaysia when compared to the global setting. Hence, despite the higher markup, essential generic drugs remain below the recommended MPR.

The MPR of essential innovator medicines, in particular anti-infectives, were observed to be high. It is possible that the high use of innovator anti-infectives in private hospital facilities, with minimal market competition, causes the large variation of anti-infective prices. This is a common observation and has also been observed in Thailand, India, and other developing countries. ${ }^{14,17,18}$ This study found that the MPR of essential innovator medicines increased as much as 80 , and thus demonstrates the stark increase in essential medicine prices in Malaysia, which particularly affect accessibility to anti-infectives. Interestingly, an MPR of 81 has also been found in other upper middle-income countries, ${ }^{17}$ which is comparable to our findings. Innovator medicines are said to dominate the market because of the patent period awarded to innovator companies. Nevertheless, while they can eventually lose their market dominance, their brand status will not be replaceable over a significant period. ${ }^{20}$ Consumers are also affected by their brand status and are often found to trust innovator over generic medicines. ${ }^{20}$ To this effect, it is vital that the affordability of essential innovator medicines be given appropriate attention. The affordability of essential innovator medicines mostly affects the anti-infective ciprofloxacin, -5-day wages and 2-day wages for a complete treatment.
The affordability of the essential innovator medicine omeprazole was one of the highest, with 7-day wages needed for a complete treatment. The high prices and affordability of anti-infectives and omeprazole were observed throughout the 5-year period.

To that end, the current findings suggest the need for a medicine pricing policy in the private sector. To address issues of affordable medicine price, various countries have implemented cost-control mechanisms including government price setting; mandatory price cuts; international reference pricing; therapeutic reference pricing; paybacks, risk sharing, or commercial contracts; generic substitutions, formulary or drug plan design; treatment guidelines; and health technology assessment. ${ }^{4,19}$ In Malaysia, where drug prices are not regulated, ${ }^{3}$ and competition in the market fails to reduce prices, national drug policies are usually favored to control medicine prices. This will allow the government to reduce unreasonable price increases. Consumers should also be educated on the effectiveness of generic medicine so as to make informed decisions based on individual affordability. Furthermore, private sectors in the local setting should also provide options of generic essential medicines to reduce out-of-pocket expenses. In light of this, the pros and cons of these cost-control mechanisms should be assessed when proposing a medicine pricing policy for Malaysia to ensure affordable health care.

\section{Conclusion}

In conclusion, irrespective of the high markup of medicine prices, medication remains largely affordable. However, despite the affordability of generic medicines, certain innovator medicines remain too expensive for a majority of the population. This is particularly a concern for essential medicines, crucial drugs in managing both patients as well as the general population. Indeed, one way to ensure affordability is educating the public on the use of generic medicines, which in turn can reduce out-of-pocket expenses. However, it should be noted that calculating affordability on the basis of the wages of unskilled government workers may lead to optimistic results since a portion of the population may earn a lot less. Nonetheless, the current work suggests that prices of essential medicines need to be fixed in order to keep them at reasonable levels. There is also a need for a national medicine pricing policy to review and regulate essential medicines, in order to ensure both generic and innovator medicine prices are capped. This may help keep out-of-pocket expenses, particularly in middle-income countries such as Malaysia, at a minimal in the private sector. 


\section{Acknowledgments}

The authors wish to thank the Director General of Health, Ministry of Health Malaysia for permission to produce this paper, Dr Salmah Bahri, Senior Director of Pharmaceutical Serviced Division in supporting this study, and the Medicine Price Branch, Pharmaceutical Services Division, Ministry of Health for providing and collecting the data used in the analyses.

\section{Author contributions}

All authors contributed toward data analysis, drafting and critically revising the paper and agree to be accountable for all aspects of the work.

\section{Disclosure}

The authors report no conflicts of interest in this work.

\section{References}

1. Cameron A, Ewen M, Ross-Degnan D, Ball D, Laing R. Medicine prices, availability, and affordability in 36 developing and middle-income countries: a secondary analysis. Lancet. 2009;373(9659):240-249.

2. Safurah J, Kamaliah MN, Khairiyah AM, Nour O, Healy J. Malaysia health system review. Health Syst Transit. 2013;3(1):44.

3. Baber ZUD, Ibrahim MIM. Affordability of medicines in Malaysia consumer perceptions. Essent Drugs Monit. 2003;33:18-19.

4. Hassali MA, Shafie AA, Babar ZUD, Khan TM. A study comparing the retail drug prices between Northern Malaysia and Australia. J Pharm Health Serv Res. 2012;3:103-107.

5. Hassali MA, Siang TC, Yen ZW, Saleem F, Alrasheedy AA. Pharmaceutical pricing in Malaysia. In: Babar ZUD, editor. Pharmaceutical Prices in the 21st Century. Switzerland: Springer International Publishing; 2014: 171-188.

6. Malaysia National Health Accounts Unit Planning Division. Malaysia National Health Accounts. Health Expenditure Report 1997-2013. Malaysia: Ministry of Health; April 2015.

7. Baber ZU, Ibrahim MIM, Singh H, Bukahri NI, Creese A. Evaluating drug prices, availability, affordability, and price components: implications for access to drugs in Malaysia. PLoS Med. 2007;4(3):e82.
8. Pharmaceutical Services Division, Ministry of Health. National Medicines Policy of Malaysia (MNMP); 2007. Available from: http://apps. who.int/medicinedocs/documents/s17798en/s17798en.pdf. Accessed October 27, 2016.

9. Pharmaceutical Services Division, Ministry of Health. Annual report 2011; 2012. Available from: http://www.pharmacy.gov.my/v2/sites/ default/files/document-upload/2011-annual-report-rsz_1.pdf. Accessed September 14, 2014.

10. World Health Organization, Health Action International. Medicine Prices - A New Approach to Measurement. Geneva: World Health Organization; 2003. Available from: http://whqlibdoc.who.int/hq/2003/ WHO_EDM_PAR_2003.2.pdf. Accessed February 15, 2015.

11. Ministry of Health. National Essential Medicines List 4th Edition; 2015. Available from: http://www.pharmacy.gov.my/v2/sites/default/ files/document-upload/national-essential-medicines-list-fourth-edition03082015.pdf. Accessed October 15, 2015.

12. Management Sciences for Health. International Drug Price Indicator Guide. Medford: Management Sciences for Health; 2014. Available from: $h$ ttp://mshpriceguide.org/en/download-files/?YearId=2014\#. Accessed September 12, 2015.

13. Hassali MA, Tan CS, Wong ZY, Saleem F, Alrasheedy AA. Pharmaceutical Prices in the 21st Century. Switzerland: Springer International Publishing; 2015.

14. Roy V, Gupta U, Agarwal AK. Cost of medicines \& their affordability in private pharmacies in Delhi (India). Indian J Med Res. 2012;136(5): $827-835$.

15. Pharmaceutical Services and Clinical Research Centre. Malaysian Statistics on Medicine 2009-2010. Petaling Jaya: Ministry of Health Malaysia; 2014.

16. Alpern JD, Stauffer WM, Kesselheim AS. High-cost generic drugs implications for patients and policymakers. NEng J Med. 2014;371(20): 1859-1862.

17. Sooksriwong C, Yoongthong W, Suwattanapreeda S, Chanjaruporn F. Medicine prices in Thailand: a result of no medicine pricing policy. Southern Med Rev. 2009;2(2):10-14.

18. Xi X, Li W, Li J, et al. A survey of the availability, prices and affordability of essential medicines in Jiangsu Province China. BMC Health Serv Res. 2015;15:345.

19. Aaserud M, Dahlgren AT, Kosters JP, Oxman AD, Ramsay C, Sturm H. Pharmaceutical policies: effects of reference pricing, other pricing, and purchasing policies. Cochrane Database Syst Rev. 2006;(2):CD005979.

20. Alrasheedy AA, Hassali MA, Stewart K, et al. Patient knowledge, perceptions, and acceptance of generic medicines: a comprehensive review of the current literature. Patient Intell. 2014;6:1-29.
Patient Preference and Adherence

\section{Publish your work in this journal}

Patient Preference and Adherence is an international, peer-reviewed, open access journal that focuses on the growing importance of patient preference and adherence throughout the therapeutic continuum. Patient satisfaction, acceptability, quality of life, compliance, persistence and their role in developing new therapeutic modalities and compounds to optimize

\section{Dovepress}

clinical outcomes for existing disease states are major areas of interest for the journal. This journal has been accepted for indexing on PubMed Central. The manuscript management system is completely online and includes a very quick and fair peer-review system, which is all easy to use. Visit http://www. dovepress.com/testimonials.php to read real quotes from published authors. 